\title{
The beneficial effects of physical exercise in the brain and related pathophysiological mechanisms in neurodegenerative diseases
}

\author{
Yan Liu ${ }^{1,2} \cdot \operatorname{Tim}_{\text {Yan }}{ }^{1} \cdot$ John Man-Tak Chu ${ }^{1,2} \cdot$ Ying Chen $^{1,2} \cdot$ Sophie Dunnett ${ }^{1}$ Yuen-Shan $\mathrm{Ho}^{3} \cdot$ \\ Gordon Tin-Chun Wong ${ }^{2} \cdot$ Raymond Chuen-Chung Chang $\mathbb{( i )}^{1,4}$
}

Received: 15 November 2018 / Revised: 20 January 2019 / Accepted: 21 January 2019 / Published online: 26 February 2019

(c) United States \& Canadian Academy of Pathology 2019

\begin{abstract}
Growing evidence has shown the beneficial influence of exercise on humans. Apart from classic cardioprotection, numerous studies have demonstrated that different exercise regimes provide a substantial improvement in various brain functions. Although the underlying mechanism is yet to be determined, emerging evidence for neuroprotection has been established in both humans and experimental animals, with most of the valuable findings in the field of mental health, neurodegenerative diseases, and acquired brain injuries. This review will discuss the recent findings of how exercise could ameliorate brain function in neuropathological states, demonstrated by either clinical or laboratory animal studies. Simultaneously, state-ofthe-art molecular mechanisms underlying the exercise-induced neuroprotective effects and comparison between different types of exercise will be discussed in detail. A majority of reports show that physical exercise is associated with enhanced cognition throughout different populations and remains as a fascinating area in scientific research because of its universal protective effects in different brain domain functions. This article is to review what we know about how physical exercise modulates the pathophysiological mechanisms of neurodegeneration.
\end{abstract}

\section{Introduction}

Physical activity is a crucial element throughout human life. The evolutionary theory suggests that humans need basal physical activities for survival [1]. In the US, approximately $26 \%$ of premature deaths can be attributed to physical inactivity [2]. In recent decades, there are compelling lines of evidence which support that exercise not only protects

Gordon Tin-Chun Wong

gordon@hku.hk

$\triangle$ Raymond Chuen-Chung Chang

rcchang@hku.hk

1 Laboratory of Neurodegenerative Diseases, School of Biomedical Sciences, LKS Faculty of Medicine, The University of Hong Kong, Pokfulam, Hong Kong SAR

2 Department of Anaesthesiology, LKS Faculty of Medicine, The University of Hong Kong, Pokfulam, Hong Kong SAR

3 School of Nursing, The Hong Kong Polytechnic University, Hung Hom, Kowloon, Hong Kong SAR

4 State Key Laboratory of Brain and Cognitive Sciences, The University of Hong Kong, Pokfulam, Hong Kong SAR against cardiovascular diseases, but also reduces the risks of several cancers and metabolic dysfunction [3]. In the central nervous system (CNS), the protective effects of both short term and long term physical exercise on neurodegeneration and cerebrovascular diseases have attracted many researchers' attention. For instance, acute aerobic exercise (AE) modulates neurotransmitter release and modulates neural circuitry [4]. Endurance AE is also known to ameliorate symptoms of major depression, prevent neuronal dysfunction, and slow down the progression of different diseases $[5,6]$. Both preclinical animal models and human patients with neurodegeneration have shown convincing evidence that exercise improves cognitive performance [7, 8]. Moreover, with the advancement of molecular techniques, researchers have discovered and identified the involvement of several molecular pathways involved in exercise-related beneficial effects [9].

On the other hand, although solid evidence has demonstrated the neuroprotective effects of exercise, whether different neuroprotective mechanisms are involved in each specific type of exercise remains one of the debated topics in the exercise medicine field. The answer to this debate is important to determine since exercise can be divided into different types, depending on the purpose of the training 
regime [10]. It remains controversial whether the therapeutic efficacy of a specific type of exercise surpasses another type of exercise, and needs further investigation.

In this review, we will present the updated findings on the beneficial effects of physical exercise in brain disorders and neurodegeneration. More importantly, we will also summarize the novel underlying molecular mechanisms about the neuroprotective actions of exercises from recent research, mainly laboratory studies. Finally, we will briefly introduce and compare different types of exercise which have been explored for their potential value in treating brain disorders.

\section{Beneficial effects of physical exercise in different brain disorders}

\section{Mental disorders}

Mental disorders are common health problems characterized by abnormal emotions, perceptions, behaviors, and relationships with others [11]. Among adults in the US, one year and lifetime morbidities of major depressive disorder (MDD) in 2011 (10.4\% and $20.6 \%$, respectively) were nearly doubled when compared with 2001 (5.3\% and $13.2 \%$, respectively) [12]. In 2017 , an estimated $18.9 \%$ of adults in the US experienced any mental illness (AMI) within the past year, while about $23.8 \%$ of the adults having AMI suffered from serious mental illness [13]. Accumulating studies have indicated that mental disorders are becoming one of the most common causes of disability and death worldwide [13]. Medications like antidepressants are available for moderate to severe mental disorders, but are not recommended for mild mental disorders and should be used with caution while dealing with patients under 18 years old due to a poor risk-benefit ratio [14].

Many studies suggested physical exercise as an effective nonpharmacologic treatment for different psychiatric problems like depression, anxiety, and dementia, either alone or as an adjunctive therapy for antidepressants/psychotropic drugs [15]. However, most of these studies had small sample sizes and included few types, frequencies, and durations of exercise. Moreover, the dose-response relationship between exercise and mental health remains unclear. In a recent cross-sectional study of a representative sample including more than one million people aged above 18, which was the largest study of its kind to date [5], the authors showed that individuals in the exercise group had 1.49 fewer days of bad self-reported mental health in the past month than individuals in the control group. Furthermore, they demonstrated that all kinds of physical exercise were associated with better mental health. The largest associations were seen for popular team sports, cycling, as well as aerobic and gym activities. This research also indicated that the best duration and frequency of exercise were $45 \mathrm{~min}$ and 3-5 times per week, respectively.

Among patients who have taken antidepressants, about $60 \%$ of them have reported adverse effects, which include negative events in sex life, work or study, and social life [16]. Another common problem in depression treatment is drug and/or psychotherapy resistance. Treatment-resistant depression (TRD) is a complex condition hardly reaching full remission, with very few "next choice" treatments. Mota-Pereira and colleagues showed that a 3-month walking exercise program improved all depression and functioning parameters in TRD patients. In addition, $26 \%$ of these patients met the criteria of remission [17], suggesting that moderate-intensity exercise might be a helpful and effective adjuvant therapy for TRD. Similar findings are reported with schizophrenia, which is a major psychiatric disease that affects approximately 24 million people worldwide [18]. Antipsychotic drugs are effective when dealing with the positive symptoms in schizophrenia, but can induce many side effects, such as weight gain and metabolic syndromes [19]. Furthermore, negative symptoms, which are highly associated with the functional outcome of schizophrenia patients, show poor response to antipsychotic drugs [20]. Interestingly, physical exercise has not only been demonstrated to reduce overall symptoms in schizophrenia, but also was found to be more effective in dealing with negative symptoms than positive symptoms [21]. These benefits suggest that physical exercise could be a therapy to decrease the negative symptoms in patients with schizophrenia.

\section{Neurodegenerative diseases}

Over the last decade, with a continually aging population, age-related neurodegenerative diseases are dramatically becoming more prevalent and represent one of the major health problems in society. The etiology of neurodegenerative diseases is multifactorial and complex, including not only genetic predispositions, but also environmental and endogenous factors. Nutritional deficiencies, hypertension, diabetes, hypercholesterolemia, obesity, and inflammation are associated with the onset and the deterioration of neurodegenerative diseases [22]. Physical exercise has been suggested as one of the best lifestyle interventions for both healthy aging and patients with neurodegenerative diseases including Alzheimer's disease (AD) and Parkinson's disease (PD).

$\mathrm{AD}$ is a progressive neurodegenerative disease affecting about 40 million people globally, and the number of patients is expected to triple by 2050 [23]. At present, AD patients are commonly treated with combined pharmacological treatment and supportive therapy, such as counseling 
and social care, to slow down the progression of the disease, and no disease-modifying treatment exists yet. There are promising findings in clinical studies that demonstrate physical exercise as an effective treatment to AD patients, which may even be a disease-modifying therapeutic approach [6, 24]. The beneficial effects of physical exercise include stimulating the release of neurotrophic factors, antiinflammatory effects, and induction of angiogenesis [6]. Furthermore, accumulating evidence shows that exercise is associated with decreased deposition of $A \beta[24,25]$ and improvement of tau pathology [26] in the brain. However, it might be too early to reach any definite conclusion as the quality of current studies varies with sample size and definite diagnosis of disease; also the type, duration, and frequencies of physical exercise were different during these studies. High-quality studies with a large sample size are needed to illustrate the relationship between exercise and the pathology of $\mathrm{AD}$.

PD is a mobility-related neurodegenerative disease directly related to the degradation of the nigrostriatal pathway, in which the extent of degeneration predicts increased disability and mortality in patients [27]. Previous studies suggested that exercise ameliorated a variety of symptoms in PD patients, including not only executive dysfunction, but also psychiatric problems and cognitive impairment [28]. A recent clinical trial, which was designed to investigate the dose-response of treadmill exercise to PD, showed that only high-intensity exercise successfully improved motor symptoms of PD patients [29]. Therefore, the intensity of exercise is an important factor to optimize its effect on symptom remission and disease progression in PD. Moreover, animal studies demonstrated that exercise could rescue the loss of dopaminergic neurons and fibers, as well as decrease the expression of $\alpha$-synuclein in the nigrostriatal region [30, 31], which emphasized the therapeutic potential of exercise as a disease-modifying treatment for PD.

\section{Acquired brain injuries}

Acquired brain injuries (ABI) include traumatic brain injury (TBI) and stroke. More than ten million people suffer from TBI annually worldwide, which lead to temporary brain dysfunction or permanent mood, physical, and cognitive deficits. Only a few noninvasive interventions have been shown to be beneficial to the brain after TBI, among which, physical rehabilitation is one of the most promising strategies to promote functional recovery after TBI [32]. Clinical studies suggested that exercise could improve fatigue and enhance recovery of cognitive functions in patients who have suffered from TBI $[33,34]$. On the other hand, animal experiments suggested that treadmill exercise might be an important mediator to enhance the survival of Purkinje neurons, to help overcome TBI-induced apoptotic neuronal death, and to suppress the formation of reactive astrocytes [35]. In addition, the effects of exercise preconditioning on TBI might be associated with increased expression of neuroprotective genes and proteins including vascular endothelial growth factor (VEGF) and erythropoietin in the brain [36].

Stroke is the second leading cause of death and adult disability worldwide, affecting approximately 15 million individuals annually. Approximately 50 to $75 \%$ of all stroke survivors have residual physical or cognitive impairments [37]. Evidence suggests that patients with cardiovascular disease, diabetes, dyslipidemia, obesity, and physical inactivity are at an increased risk for stroke [38]. Therefore, the application of exercise in the prevention of stroke is more like an etiological treatment, through the improvement of a variety of conditions and diseases. The typical beneficial effects of exercise include lower body weight, better control of hypertension, glucose tolerance, decreased LDL cholesterol level, and an overall reduction in the risk of cardiovascular diseases and diabetes mellitus [39]. A clinical study showed that highly active individuals exhibit a $21 \%$ lower risk of ischemic stroke and a $34 \%$ lower risk of hemorrhagic stroke [40]. The benefits of exercise have also been demonstrated in post-stroke intervention. Physical training after stroke improves walking speed, balance, optimal recovery and promotes the earlier return to an independent life [41].

\section{Pathophysiological mechanisms}

\section{Neurotrophic factors}

The induction of neurotrophic factors is considered as a central mechanism that mediates the benefits of physical exercise on brain functions. Exercise has been shown to be associated with the expression of neurotrophic factors including brain-derived neurotrophic factor (BDNF), insulin-like growth factor 1 (IGF-1), and VEGF, thereby promoting neural plasticity and adult hippocampal neurogenesis [42].

BDNF is a neurotrophic growth factor that is essential to neuronal survival, growth, differentiation, as well as synaptic plasticity $[43,44]$. Notably, it has been found to be involved in adult neurogenesis and myelin repair [45]. BDNF is widely expressed in the CNS, with a particularly high concentration in the hippocampus and cortex, and has also been found in the peripheral nervous system as a proxy of cortical BDNF [44]. Furthermore, a decrease of BDNF in the periphery and CNS is found in many neurodegenerative and psychiatric diseases [46]. Exercise induced the upregulation of BDNF, both in circulation and in the brain, and the increased levels of BDNF were associated with 
improved cognitive function [42, 46, 47]. Although exercise increased the levels of BDNF mRNA and proteins in skeletal muscle, this muscle-derived BDNF was not released into circulation. Instead, the brain contributed $70-80 \%$ of the BDNF in circulation during exercise [48]. It is suggested that the increased expression of BDNF in the brain, especially in the hippocampus or dentate gyrus (DG), attenuates cognitive deterioration and improves memory formation.

The underlying mechanism of how exercise mediates the expression of BDNF in the brain remains unclear. Wrann and colleagues found that exercise increased BDNF expression in the hippocampus via the PGC- $1 \alpha /$ FNDC5 pathway [49]. They demonstrated that endurance exercise induced the expression of the Fndc5 gene in the hippocampus, accompanied with the expression of peroxisome proliferator-activated receptor gamma coactivator- $1 \alpha$ (PGC$1 \alpha$ ), which co-regulated the expression of neuronal fibronectin type III domain-containing protein 5 (FNDC5) with estrogen-related receptor $\alpha$. In addition, overexpression of FNDC5 in the periphery increased the expression of BDNF in the hippocampus, indicating that the exercise-induced upregulation of $\mathrm{BDNF}$ in the hippocampus was mediated via both the neuronal PGC- $1 \alpha /$ FNDC5 pathway and the muscle-derived irisin (the secreted form of FNDC5) in serum. On the other hand, evidence also suggested that exercise induced an accumulation of metabolite-like ketone bodies in the hippocampus, which promoted the expression of BDNF by altering the Bdnf promoter [50]. Moreover, accumulating bodies of evidence showed that the effect of exercise on brain BDNF expression was regulated by multiple genetic factors including the Val66Met mutation [51], APOE\&4 allele carriers [7] and methyl CpG binding protein 2 [45].

VEGF is a hypoxia-induced protein, which is expressed in different kinds of cells, such as smooth or skeletal muscle cells, endothelial cells, macrophages and glial cells [42]. VEGF plays a critical role in vasculogenesis and angiogenesis by promoting the formation of blood vessels and increased blood flow in both the peripheral nervous system and CNS [42, 44]. Several reports showed that increased levels of brain-derived VEGF from exercise reduced ischemic injury and attenuated ischemia-induced cognitive deficits by promoting the proliferation of progenitor cells and neuronal differentiation in the ischemic penumbra [52, 53].

Naturally, exercise can induce accumulation of lactate, thereby activating hydroxycarboxylic acid receptor 1 (HCAR1) and improving the activity of downstream pathways like ERK1/2 and Akt signaling, which are linked to the expression of VEGF as well as angiogenesis in the hippocampus [54]. A recent study indicated that exercise increased the levels of VEGF and angiogenesis in the brain through the lactate receptor HCAR1 [54]. In the ischemic brain, exercise-induced neurogenesis and angiogenesis rely on enhanced VEGF expression, resulting in the reduction of infarct volume and alleviation of cognitive decline. On the other hand, in a conditional skeletal myofiber-specific VEGF gene ablation mouse model, it was shown that muscle-derived VEGF induced by exercise increased the levels of VEGF in the hippocampus [55]. More interestingly, skeletal muscle-derived VEGF has been reported to enhance neurogenesis in the hippocampus [42]. One hypothesis for this phenomenon is that exercise-induced VEGF in the periphery can cross the blood-brain barrier (BBB) and mediate neurogenesis and angiogenesis in CNS, similar to the mechanisms of IGF-1. The BBB is formed by a monolayer of endothelial cells, supplemented with capillary pericytes and astrocyte perivascular end-feet. Tight junctions are also present to limit the paracellular flow of substances across the BBB [56]. The mechanism of how VEGF crosses the BBB remains an issue to be investigated, though it is expected that exercise could alter the physical status of endothelial cells, leading to increased BBB permeability $[57,58]$.

IGFs are proteins that have highly similar sequences to insulin. Serum IGF-1 has emerged as a key growth factor to modulate synaptic plasticity, neurotransmission, and neurogenesis in the adult hippocampus [59]. It was demonstrated that a lack of serum IGF-1 caused cognitive impairment and depressive behavior [59], while diminished $I g f-1$ gene expression with aging was associated with cognitive decline [60]. It has been reported that muscle-derived IGF-1 enhanced muscle mitochondria functions and the levels of IGF-1 in the hippocampus [57]. The high BBB permeability of IGF-1 allows serum IGF-1, instead of other neurotrophic factors, to access the brain and increase uptake of IGF-1 in the brain; this underlying mechanism may be linked to the regulation of IGF binding proteins (IGF-BPs) and expression of IGF-1 receptors on the BBB [59]. Moreover, in some pathological statuses, exercise is able to attenuate neurodegeneration or neuropathological behaviors by altering cytokine production, which indirectly restores normal IGF-1 levels [61].

\section{Neurotransmitters: serotonin and kynurenine metabolism}

Cerebral serotonin (5-hydroxytryptamine, 5-HT) homeostasis has been implicated in mood and cognition, thereby fundamentally impacting the pathophysiology of brain disorders such as depression and cognitive dysfunctions. In accordance with the theory of 5-HT dysregulation in depression and anxiety, selective serotonin reuptake inhibitors (SSRIs) that primarily target the CNS 5-HT system are now the first-line treatment for MDD and anxiety disorders [62]. Furthermore, the pharmacological effects of SSRIs are indispensable for hippocampal neurogenesis. 
Evidence from experiments in rats has demonstrated that exercise increased the levels of 5-HT in different brain regions, including the cerebellum, striatum, hippocampus, and frontal cortex [63]. It has been recently reported that central 5-HT is an essential positive modulator of neurogenesis that specifically functions in response to running stimuli. In addition, Kondo and colleagues demonstrated that the 5-HT3 receptor was essential for 5-HT action in hippocampal neurogenesis and antidepressant-like behavior induced by exercise, but is not responsible for enhancing learning and memory [64]. Hence, more work is required to demonstrate the precise mechanisms of action of 5-HT in cognitive function induced by exercise.

In human studies, physical exercise increases 5-HT concentrations in urine, whole blood (with mainly platelets storing 5-HT), as well as in serum (free 5-HT) [65]. Although it was believed that 5-HT could not cross the $\mathrm{BBB}$, a recent study revealed the presence of the 5-HT transporter in vascular endothelial cells in the BBB [66]. In addition, evidence has indicated that central 5-HT levels were positively correlated with 5-HT levels in the periphery [67]. These findings suggest that peripheral 5-HT levels could be a rough indicator for central 5-HT concentrations. On the other hand, changes in 5-HT precursors, such as tryptophan, are also used as peripheral proxies of cerebral 5HT metabolism. Unlike 5-HT, tryptophan can be transferred from the brain to the periphery across the BBB. Melancon and colleagues showed that physical exercise increases the availability of tryptophan to the brain during exercise in the elderly [68].

Other than acting as a peripheral predictor of cerebral 5HT levels, tryptophan has drawn a lot of attention in recent studies on depression because of its major degradative products, kynurenines. 5-HT dysregulation is believed to play a major role in depression, and it has been long proposed that 5-HT deficiency was mainly due to the shift of tryptophan metabolism from 5-HT synthesis to kynurenines [69]. Furthermore, kynurenic acid (KYNA) is a main product of kynurenine metabolism, which has a higher affinity to $\alpha$-7-nicotinic acetylcholine $(\alpha 7 \mathrm{nACh})$ receptors and $\mathrm{N}$-methyl-D-aspartate (NMDA) receptors, acting as an antagonist on NMDA and $\alpha 7 \mathrm{nACh}$ receptors. Since $\alpha 7 \mathrm{nACh}$ receptors and NMDA receptors are essential for normal synaptic function and memory formation, the accumulation of KYNA might contribute to the cognitive impairment observed in depression and dementia [70]. Kynurenine is actively transported across the BBB, while its metabolites, such as KYNA and quinolinic acid, cannot enter the brain freely from circulation. Based on these important principles, Agudelo and colleagues found that exercise enhanced the peripheral breakdown of kynurenine to KYNA in skeletal muscle, thus reducing plasma kynurenine to protect the brain from stress-induced depression
[71]. In this groundbreaking study, the authors proposed for the first time that exercise is beneficial to depression by targeting kynurenine breakdown in skeletal muscle to facilitate central kynurenine clearance, without needing to cross the BBB. More interestingly, as mentioned above, circulating kynurenine can be transported into the brain by the large amino transporter 1 (LAT1) in the BBB. A new study showed that peripheral administration of leucine, which has a high affinity for LAT1, prevented the entry of kynurenine into the brain and attenuated inflammationinduced depression-like behavior in mice [72].

\section{The role of myokines in muscle-brain crosstalk}

In recent years, skeletal muscle has been proposed to be a secretory organ. Accordingly, myokines are defined as cytokines and peptides that are secreted from skeletal muscle fibers and exert either autocrine, paracrine, or endocrine effects [73]. The secretion and release of myokines are mainly mediated by the muscle contractioninduced factors, also referred to as "the exercise factor". Skeletal muscle accounts for about $40 \%$ of total body mass in humans, therefore, exercise can be a powerful way to impact systemic metabolism and functions in other organs by mediating the secretion of myokines [74]. Studies showed that exercise promoted the production of several hundred myokines in muscle; some of which, like PGC-1 $\alpha$, Irisin and Cathepsin B, have been shown to be important parts of the muscle-brain crosstalk. Furthermore, we also present some evidence suggesting fibroblast growth factor 21 (FGF-21) and SPARC as novel brain-beneficial myokines.

PGC- $1 \alpha$ is dramatically up-regulated during physical exercise and is considered to be a major mediator of the beneficial effects of exercise to the brain [49]. Although initially reported as a transcriptional co-activator of oxidative metabolism and differentiation-induced mitochondrial biogenesis in brown fat [75], subsequent studies demonstrated the high expression levels of PGC- $1 \alpha$ in cells including cardiac myocytes, neurons, and skeletal muscle cells, which have a relatively higher demand of energy [76]. One animal study has shown that activating the expression of PGC- $1 \alpha$ by astrocytic nerve growth factor successfully restored the behavior deficits, sensorimotor disorders, and neuronal loss in a Huntington's disease (HD) model [77], probably because it negatively regulated the activity of extrasynaptic NMDA receptors, thereby reducing excitotoxicity in the cortical neurons [78]. PGC- $1 \alpha$ has also shown neuroprotective effects in a MPTP animal model of PD [27], depression and other neuropsychiatric disorders [71, 74]. In addition, researchers found that PGC- $1 \alpha$ played an important part in the formation and maintenance of neuronal dendritic spines and synapses in the hippocampus [79]. 
FNDC5 was identified as a PGC- $1 \alpha$-dependent myokine a few years ago [80]. During physical exercise, FNDC5 is cleaved and secreted from muscle into the circulation as irisin [81]. Irisin can act on subcutaneous fat, activating the thermogenic program and giving the white adipose tissue "brown fat"-like functions [80]. Recent studies have shown that the target of irisin is not limited to adipocytes since FNDC5 was also found throughout the brain to mediate cell differentiation [82]. Furthermore, studies have shown that the irisin in the brain was beneficial to neurons beyond neonatal development. Centrally administered irisin successfully reduced neuronal apoptosis and increased the expression of BDNF in a mouse model of stroke [83], and also produced antidepressive effects and modulated neuroplasticity-related genes in a mouse model of depression [84]. Interestingly, Wrann and colleagues found that peripheral delivery of FNDC5 by adenoviral vectors increased $B d n f$ expression in the hippocampus [49]. This study raised suspicions that irisin in the blood can actually go through the $\mathrm{BBB}$ or bind to receptors on endothelial cells [74], showing that peripheral irisin and centrally expressed irisin can have synergistic effects on the brain.

Cathepsin B (CTSB) is a lysosomal cysteine protease found all over the body [85]. It is currently under investigation for its potential use as a tumor marker as increased expression of this compound is observed in premalignant and malignant cells [86]. However, one recent study unearthed its alternative function as a myokine communicating with the nervous system. Increased CTSB levels were found in the plasma of rhesus monkeys and humans under exercise; as well as the gastrocnemius muscle and plasma in mice after running [87]. In the same study, CTSB was found to be able to cross the $\mathrm{BBB}$ and promote the induction of BDNF and doublecortin (DCX), which were responsible for neuronal survival and brain development [88], respectively. The P11 protein was suggested to be involved in CTSB-mediated DCX expression, while the pathway involved in CTSB-mediated BDNF expression remains unknown [87]. Although exercise was shown to increase CTSB transcripts in the brain directly, it is suggested that this direct stimulation is supplemented by peripheral CTSB myokine signaling [89].

FGF21 is a peptide hormone mainly produced by the liver, but is also expressed in skeletal muscles and adipose tissue. It is known to have beneficial metabolic effects like weight loss and improved glycaemia, which rely upon its role on the regulation of fatty acid oxidation and glucose metabolism [90]. Therefore, FGF21 is regarded as hepatokine and adipokine, acting as messengers of the liver and adipose tissue under dietary stimulation or metabolic stress [90]. It was demonstrated that the concentrations of FGF21 were increased in both skeletal muscles and serum after acute exercise [91]. FGF21 can cross the BBB. Although
FGF21 was previously thought to be expressed only peripherally, it was also found in the CSF of both mice and humans $[92,93]$. FGF21 in the brain was shown to interact with the brain through its co-receptors, $\beta$-Klotho, and FGFR-1, thereby producing effects such as modulating sympathetic nerve output to brown fat, controlling circadian behavior and neuroprotection [90, 94]. Furthermore, Kuroda and colleagues found that peripherally derived FGF21 leaked into the brain after injury and promoted remyelination in a mouse model of demyelination [95]. Hence, although very few studies have demonstrated the direct link between exercise-induced upregulation of FGF21 and the beneficial effects of exercise in the brain, FGF21 has great potential to be a novel myokine that helps to promote brain health.

Osteonectin, also known as SPARC, is a bone glycoprotein that mediates bone mineralization and mineral crystal formation. Its relationship with muscles remained hidden until a recent study revealed its alternative function as a myokine [96]. Increased secretion of SPARC was found in the gastrocnemius muscle after $60 \mathrm{~min}$ of exercise in a mouse model, while in vitro cell studies found out that increased SPARC translation was responsible for the increased secretion. These results were consistent with study in humans, as exercise was shown to increase SPARC in the circulation [96]. SPARC is also expressed in the brain and has many different functions. SPARC knock-out mice had increased levels of anxiety and depression, but the expression of SPARC in adult mouse hippocampus was found to reduce depressive behaviors in SPARC knock-out mice [97]. SPARC acts synergistically with BDNF to promote the outgrowth of retinal ganglion cells via Akt phosphorylation and BDNF-induced Erk1/2 phosphorylation [98]. Mature, ramified microglia also expressed SPARC, and knock-out of the gene resulted in altered microglial morphology, with increased branching and elongated microglial processes when compared to the control [99]. Although muscle-derived SPARC has not been shown to cross the BBB yet, the multitude of its effects on the brain, as well as its dependency on exercise for secretion, make SPARC a potential candidate for a myokine that could benefit the brain.

\section{Anti-Inflammatory effects of exercise}

Clinical studies demonstrated that persistent systemic inflammation is a common feature in many neurological disorders, including depression, AD, PD, and HD [100]. Chronic systemic inflammation predisposes individuals to insulin resistance, endothelial cell dysfunction, and atherosclerosis and exacerbates neuroinflammation, thereby contributing to neuropathological changes in the brain [101]. Exercise is advocated as a powerful anti-inflammatory 


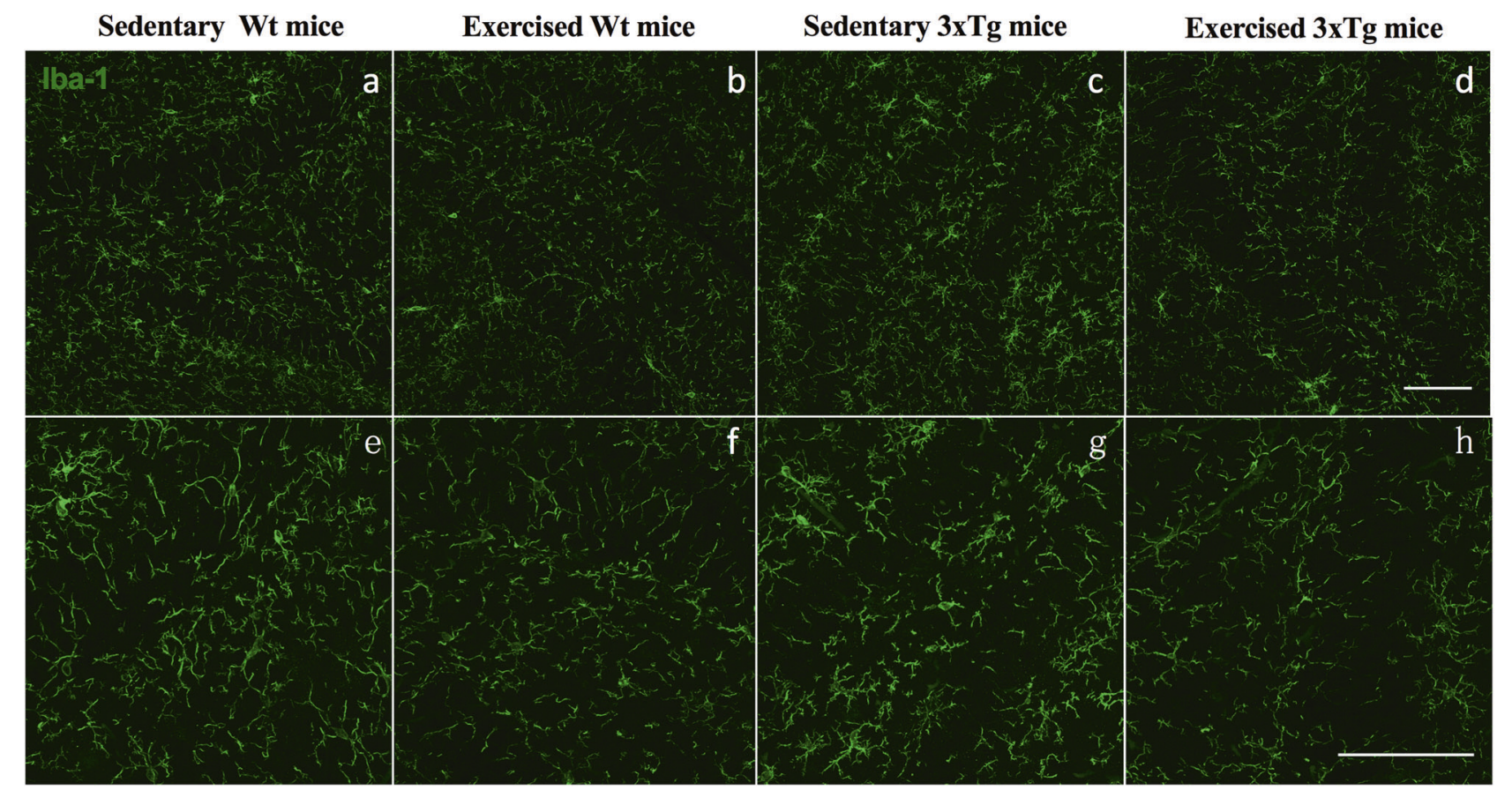

Fig. 1 Five-weeks of RE reduced microglia activation in DG region of 10-month wild type and 3xTg mice. Representative stacked confocal images of IBA-1 Immunoreactivity in (a-d) low magnification, $\times 20$ and (e-h) high magnification, $\times 40$. (Scale bar: $20 \mathrm{~mm}$ )

therapy for depression and neurodegeneration diseases. Rethorst and colleagues found that a high level of TNF- $\alpha$ was linked to poor response to antidepressive effects of exercise in MDD [102]. Specifically, evidence suggested that exercise could protect the brain from inflammation, either by directly mediating inflammatory cytokines [8], or reducing pro-inflammatory adipokines through the muscleadipose crosstalk [103], thereby rescuing the secretion of growth factors and promoting neural plasticity and neurogenesis. Furthermore, exercise has also been suggested to mediate the innate inflammatory response through the sympathetic nerves or the hypothalamic-pituitary-adrenal axis as a physiological stressor [104].

The direct effect of exercise on inflammation can be varied depending on the different pathophysiological conditions of individuals, since both pro-inflammatory cytokines and anti-inflammatory cytokines were increased immediately in the circulation after exercise [57]. Although there was previously a concern that exercise might aggravate symptoms of diseases like TBI, stroke, and multiple sclerosis by exaggerating inflammation [105], exercise has now been suggested as a protective intervention to improve symptoms and reduce overall inflammatory conditions of those diseases if performed during the appropriate time. Animal studies demonstrated that exercise could directly improve the immune condition of the brain by increasing the levels of IL-10 in the hippocampus of aged rats [106], and by reducing the levels of
IL-1 $\beta$ in the brain of a $\beta$-amyloid-induced mouse model of AD [107]. Furthermore, physical exercise has also been shown to prevent brain inflammation in stroke [108]. Some data indicated that physical exercise could reduce the production of pro-inflammatory cytokines in the brain by promoting the clearance of $\mathrm{A} \beta[24,25]$, which has proinflammatory effects itself. In line with these studies, we demonstrated that 5 -weeks of resistance training reduced the activation of microglia, which were important sources of pro-inflammatory cytokines, in the DG of both wild type and 3xTg male mice (Fig. 1). In addition, another study showed that exercise might protect against inflammation-induced neurological deficits in a TBI model by activating the HSP70/NF-kB/IL-6/synapsin I axis [109].

One prominent effect of exercise on the body is reducing the number and improving the functions of adipocytes, which are important sources of peripheral inflammatory cytokines $[110,111]$. Recent data also demonstrated a direct anti-inflammatory effect of irisin by suppressing the production of several major pro-inflammatory cytokines including TNF- $\alpha$, MCP-1, and IL- 6 by adipocytes. In addition, the presence of irisin inhibited the activity of a well-known inflammatory transcription factor, nuclear factor kappa B [103]. More importantly, an adipocyte-secreted hormone, adiponectin, which is an insulin-sensitizing and anti-inflammatory factor, has been shown to be essential to the physical exercise-induced antidepressant effects and 
hippocampal neurogenesis in an adiponectin-deficient mouse model [111].

\section{Mitochondrial-mediated mechanisms}

Mitochondria are double-membrane bound organelles most widely known for their role in aerobic respiration [112]. However, with an increasing number of studies that are focused on this intracellular powerhouse, it has been revealed that ATP production is only one of the many functions. Notably, mitochondria have been found to play a role in exercise-induced neuronal benefits, which might occur through the mediation of mitochondrial biogenesis and mitophagy [113]. Mitophagy is the autophagic elimination of damaged mitochondria. It can aid the restoration of a healthy mitochondrial population by removing the stressed or damaged parts of the mitochondria [114]. Mitochondrial fusion and biogenesis could rescue mildly dysfunctional mitochondria, while mitochondrial fission and mitophagy could clear damaged mitochondria so that they would not interfere with healthy mitochondria. This interplay between mitochondrial biogenesis and mitophagy could maintain the health of mitochondria, contributing to the overall neuronal health together.

The SIRT1-PGC1- $\alpha$ axis is an important compensatory mechanism counteracting excessive mitochondrial fission and degradation that predominates neurodegenerative pathologies [115]. Several studies found that the SIRT1PGC1- $\alpha$ axis was associated with exercise-induced mitochondria-mediated neuroprotection by increased mitochondrial biogenesis [116, 117]. Silent information regulator T1 (SIRT1) is an enzyme that deacetylates peroxisome PGC$1 \alpha$, which increases its transcriptional activity. Increased levels of SIRT1 and PGC1- $\alpha$ were found after moderate long-term exercise in rats [116] and mice [117], suggesting that exercise can upregulate the SIRT1-PGC1- $\alpha$ axis. Furthermore, these studies demonstrated various mitochondriarelated beneficial effects of exercise in the brain, including increased mtDNA content [116], decreased p53 acetylation, increased activation of 5'AMP-activated protein kinase (AMPK), as well as a concomitant increase in the content of mitochondrial respiratory complexes [117]. The above evidence suggests that exercise-induced activation of SIRT1-PGC1- $\alpha$ can increase mitochondrial biogenesis and promote neuronal health.

Exercise can also provide protective effects for the brain by promoting mitophagy through mediating the AMPKUlk1 pathway. It was found that LC3-II (a marker for autophagy) was co-localized with mitochondria and the autophagic flux was increased following exhaustive treadmill running in mice [118]. Moreover, a recently published study demonstrated that AMPK phosphorylation of Ulk1 was essential for exercise-induced mitophagy [114].
Exosomes: a bridge between muscle and brain

Exosomes are "saucer-shaped" vesicles [119] first discovered within maturing mammalian reticulocytes in 1987, which have a phospholipid bilayer and measure between 30 and $100 \mathrm{~nm}$ [72]. They are formed intracellularly by the inward budding of endosomes, with the endosome surrounding them termed multivesicular bodies (MVB). MVB can then fuse with the plasma membrane to release the exosomes to extracellular space. Exosomes can be found in various body fluids, including plasma, saliva, urine, amniotic fluid, synovial fluid, pleural effusions, and malignant ascites [119]. It was demonstrated that exosomes can be secreted into the blood after exercise as signal transducers, communicating with target cells via surface interaction or membrane fusion, which in turn mediated the release of the exosomal contents into the target cells and activated downstream signaling [120].

Exosomes were suggested to be key players in enabling muscle-tissue crosstalk during exercise in a recently conducted study. Increased plasma levels of myokines, as well as proteins highly enriched in small extracellular vesicles, were observed in humans after an hour of cycle exercise [121]. Exosomes packed with hundreds of peptides were also found to be released from skeletal muscles in mice [122]. In a pilot study, an exosome marker, ALG-2interacting protein $\mathrm{X}$ was found to be severely depleted right after acute endurance exercise, suggesting the presence of exosomes in muscles and their exercise-dependent release. Moreover, up to $75 \%$ of reported myokines were found to exist in exosomes [123], highlighting the possibility of exosomes mediating exercise-induced myokines release.

It is well known that the BBB is the most important insuperable barrier for many signal molecules from the periphery to interact with the brain. Molecules flowing freely within the plasma cannot pass through the BBB easily, but exosomes are capable of migrating across the BBB via the transcellular route [124]. Multiple pharmacological studies aimed at treating brain diseases like primary brain cancer [125] and PD [126] had employed the use of exosomes as a means to deliver drugs to the brain, while others merely demonstrated that exosomes could cross the BBB [124] or deliver genetic cargo like siRNA across the BBB [127]. Despite the diverse aims and designs of these studies, they have consistently demonstrated the successful migration of exosomes across the BBB.

As the above evidence suggests, exosomes carrying myokines are released during exercise. Moreover, exosomes also have a favorable interaction with the BBB. Taken together, these results lead us to believe that exosomes might have an important role in the muscle-brain crosstalk. 
Brain changes during exercise-induced hippocampal neuronal activation

Regarding the previously discussed circulating myokine hypothesis, exercise exerted its effects by blood-borne muscle-derived factors. Recently, it was proposed that the direct neuronal stimulation to the brain during exercise might also be involved with the beneficial effects of exercise in the brain [128]. Neuronal activity could induce widespread changes in the structure and function of the brain, including the modulation of membrane receptors, neurotrophic factors, dendritic spines, and even blood vessel structure [129]. Many studies have shown that hippocampal neurogenesis was affected following electrical activity and neuronal activation [130, 131]. Specifically, these studies not only showed that neurogenesis occurred in the presence of stimuli like $\mathrm{Ca}^{2+}$ channel and NMDA activation, but also demonstrated that these stimuli alone are sufficient to promote differentiation and proliferation of neurons. Activation of the neurons in the hippocampus during exercise has been reported in different rodent models $[129,132]$, and the specific form of neuronal activation has been demonstrated as an acute expression in immediate early genes (IEG) [132, 133] changes in regional blood flow, increased firing rates of neurons in the hippocampus and simultaneous modulation of hippocampal theta oscillations $(4-12 \mathrm{~Hz})$ [134] and gamma oscillations $(30-120 \mathrm{~Hz})$ [133].

The direct relationship between the average running speed and the degree of neuronal activity has been demonstrated by the changes of the IEG, which reflect the extent of chronic activation since high levels of IEG correlate with increased gene expression and cell remodeling [135]. Induction of IEG was originally thought to occur when the animal explored a novel environment [136], but animal models of exercise have shown that chronic exercise induced a proportional increase in IEG-activated neurons [137]. Consistently, electrophysiological studies also showed a close relationship between the firing rates of hippocampal neurons and the instantaneous moving speed of rodents in animal models including voluntary wheel running [138], treadmills [139] and mazes [140]. Interestingly, another experiment, which compared active and passive movement, found that spatial movement without actual physical activity was not enough to excite hippocampal neurons [141]. This finding suggests that neuronal activation during exercise is mainly attributed to the amount of physical activity, instead of the novelty of experience or spatial navigation.

Exercise was also found to elicit synchronized hippocampal neuronal activations called theta waves, during both initiation of exercise and ongoing movement [134]. Theta rhythms are electrical waves ranging from 4 to $8 \mathrm{~Hz}$, generated from hippocampal regions like CA1-3 and DG [128]. It is suggested that the inputs from the medial septum and nucleus of the diagonal band of Broca (MS-DBB) to the hippocampus are responsible for synchronizing hippocampal neuronal activity during theta oscillation [142], with modulations of the MS-DBB pathway coming from the posterior hypothalamic nucleus [143] and the vesicular glutamate transporter 2-positive neurons [139]. The activities of the MS-DBB axis, as well as the medial entorhinal cortex, are both shown to predict theta waves and the speed of locomotion [143].

\section{The common and distinct pathophysiological changes induced by different types of exercise}

As mentioned previously, great deals of studies have revealed the effects of physical exercise on cognition and related pathophysiological mechanisms. In general, there exists four types of exercise, which are AE (e.g., running, walking, and yard work), resistance exercises (RE, e.g., weightlifting and some types of gym training that use a resistance band or an individual's own body weight), balance exercises (e.g., Tai Chi) and flexibility exercises (e.g., Yoga). Although most studies focus on AE, nearly all types of exercise have been demonstrated to reduce depression, enhance cognitive function, and promote the recovery from ABI [5, 144]. Furthermore, the combination of different types of exercises led to greater benefits in brain functions $[145,146]$.

It is suggested that different types of exercise induce similar physiological and structural changes in the brain. First of all, the levels of BDNF [147, 148] and serotonin $[149,150]$ in serum are increased in different types of exercise. Secondly, different types of exercise showed similar anti-inflammatory effects by promoting the induction of anti-inflammatory factors and inhibiting the expression of pro-inflammatory factors, thereby contributing to a healthy immunologic environment $[150,151]$. However, some types of exercise showed greater benefits than other types of exercise to the brain by modulating specific brain functions and pathophysiologic markers, despite the similar cognitive and neuroplastic outcomes with other types of exercise. A systematic review suggested that although both $\mathrm{AE}$ and RE improved visuospatial function in older humans, AE induced greater benefits in cognitive function and executive function than RE [146]. In addition, it was also demonstrated in a population-based analysis that AE showed a stronger antiinflammatory effect compared to RE, despite the fact that they both reduced the levels of inflammatory markers [152]. 
Accumulating bodies of evidence from neuroimaging studies revealed that different types of exercise have divergent effects on the structure of the brain. It was reported that $\mathrm{AE}$ increased the volume of the right hippocampus and prevented the atrophy of the medial temporal lobe and anterior cingulate cortex [153]. Despite little research on other types of exercise, a six-month clinical trial showed that RE increased the volume of the hippocampus [154], while Tai Chi increased the grey matter volume [155] and yoga reduced the volume of the amygdala [156]. Taken together, these results suggest that different types of exercise might induce structural changes in diverse brain regions. However, the current findings are from limited studies that varied in frequency and duration of exercise, and most importantly, the condition of the participants. Therefore, more studies with larger sample sizes and involving similar populations should be conducted in the future to illustrate the diverse effects of different types of exercise on the structure of different brain regions.

Cassilhas and colleagues demonstrated that, in a rat model, both $\mathrm{AE}$ and RE improved hippocampus-dependent learning and memory function. They found that AE preferentially promoted the induction of BDNF, while RE preferentially increased the levels of IGF-1 in the hippocampus [157]. In addition, $\mathrm{AE}$, rather than RE, induced neurogenesis in the DG of adult male rats [158]. In line with these results, it was found that $\mathrm{AE}$ and $\mathrm{RE}$ specifically induced different isoforms of PGC- $1 \alpha$, which has been mentioned above for its role as an important myokine. Specifically, PGC- $1 \alpha$ can be differentially spliced and translated into different isoforms, including PGC-1 $\alpha 1$ (the previously described PGC- $1 \alpha$ ), $-\alpha 2,-\alpha 3$ and $-\alpha 4$, performing functions like promoting mitochondrial biogenesis, fatty acid oxidation and angiogenesis [159]. The levels of PGC$1 \alpha 4$ are most dramatically increased during RE both in mouse and human muscle [160]. Interestingly, it was found that SIRT3 and PGC-1 $\alpha$ (1) levels were increased following $\mathrm{AE}$, but not $\mathrm{RE}$ [161], indicating that $\mathrm{AE}$ and $\mathrm{RE}$ promote the induction of PGC- $1 \alpha 1$ and PGC- $1 \alpha 4$, respectively. Furthermore, since $\mathrm{AE}$ was shown to increase BDNF expression in the hippocampus via the PGC-1 $\alpha(1) / F N D C 5$ pathway [49], while PGC-1 $\alpha 4$ is known to regulate genes in the IGF-1 pathways [159], these findings, which are consistent with the findings of Cassilhas and colleagues, suggest that $\mathrm{AE}$ and $\mathrm{RE}$ might benefit the brain via distinct pathways.

\section{Conclusion}

In conclusion, exercise will be one of the promising therapeutic strategies in preventing mental disorders, neurodegeneration, and ABI. Several molecular targets have been identified, which are critically involved in the different brain regions that could be beneficial for patients with mental disorders and neurodegenerative diseases. Exercise modulates neurotransmitter release, enhances neurogenesis, exerts anti-neuroinflammatory actions, triggers neurotrophic factor release, as well as modulates intracellular signaling to inhibit neuronal dysfunction and promote synaptic plasticity. In line with these exciting results, exercise training is shown to ameliorate different neuropathology in neurodegenerative patients. By discovering more molecular pathways which are specifically activated by exercise, potential biomarkers which reflect the advantage of exercise may be developed, and it may assist clinicians to tailor make exercise regimes for individual patients, including the type and intensity of exercise.

Nevertheless, there are still many obstacles and challenges along the research path regarding exercise in neuroprotection. As indicated in previous reports, exercise is a complicated behavior that involves the interactions between the brain and periphery. Multiple, rather than single pathways, are expected to be involved in the neuroprotective mechanisms. Future research should focus on the interaction between the periphery and brain, and how this interaction may influence subsequent neuronal dysfunction and neuropathology in the brain.

\section{Compliance with ethical standards}

Conflict of interest The authors declare that they have no conflict of interest.

Publisher's note: Springer Nature remains neutral with regard to jurisdictional claims in published maps and institutional affiliations.

\section{References}

1. Raichlen DA, Polk JD. Linking brains and brawn: exercise and the evolution of human neurobiology. Proc Biol Sci. 2013;280:20122250.

2. Young DR, Hivert MF, Alhassan S, Camhi SM, Ferguson JF, Katzmarzyk PT, et al. Sedentary behavior and cardiovascular morbidity and mortality: a science advisory from the American Heart Association. Circulation. 2016;134:e262-79.

3. Blair SN, Brodney S. Effects of physical inactivity and obesity on morbidity and mortality: current evidence and research issues. Med Sci Sports Exerc. 1999;31:S646-62.

4. Dudar JD, Whishaw IQ, Szerb JC. Release of acetylcholine from the hippocampus of freely moving rats during sensory stimulation and running. Neuropharmacology. 1979; 18:673-8

5. Chekroud SR, Gueorguieva R, Zheutlin AB, Paulus M, Krumholz HM, Krystal JH, et al. Association between physical exercise and mental health in 1.2 million individuals in the USA between 2011 and 2015: a cross-sectional study. Lancet Psychiatry. 2018;5:739-46.

6. Frederiksen KS, Gjerum L, Waldemar G, Hasselbalch SG. Effects of physical exercise on Alzheimer's Disease Biomarkers: 
A Systematic Review of Intervention Studies. J Alzheimers Dis. 2018;61:359-72.

7. Allard JS, Ntekim O, Johnson SP, Ngwa JS, Bond V, Pinder D, et al. APOE\&4 impacts up-regulation of brain-derived neurotrophic factor after a six-month stretch and aerobic exercise intervention in mild cognitively impaired elderly African Americans: A pilot study. Exp Gerontol. 2017;87:129-36.

8. Stranahan AM, Martin B, Maudsley S. Anti-inflammatory effects of physical activity in relationship to improved cognitive status in humans and mouse models of Alzheimer's disease. Curr Alzheimer Res. 2012;9:86-92.

9. Vega RB, Konhilas JP, Kelly DP, Leinwand LA. Molecular mechanisms underlying cardiac adaptation to exercise. Cell Metab. 2017;25:1012-26.

10. Hawley JA, Hargreaves M, Joyner MJ, Zierath JR. Integrative biology of exercise. Cell. 2014;159:738-49.

11. Steel Z, Marnane C, Iranpour C, Chey T, Jackson JW, Patel V, et al. The global prevalence of common mental disorders: a systematic review and meta-analysis 1980-2013. Int J Epidemiol. 2014;43:476-93.

12. Hasin DS, Sarvet AL, Meyers JL, Saha TD, Ruan WJ, Stohl M, et al. Epidemiology of Adult DSM-5 Major Depressive Disorder and Its Specifiers in the United States. JAMA Psychiatry. 2018;75:336-46.

13. Bose J, Hedden SL, Lipari RN, Park-Lee E. Key Substance Use and Mental Health Indicators in the United States: Results from the 2017 National Survey on Drug Use and Health. 2018.

14. Gartlehner G, Gaynes BN, Amick HR, Asher GN, Morgan LC, Coker-Schwimmer E, et al. Comparative benefits and harms of antidepressant, psychological, complementary, and exercise treatments for major depression: An evidence report for a clinical practice guideline from the American College of Physicians. Ann Intern Med. 2016;164:331-41.

15. Knochel C, Oertel-Knochel V, O'Dwyer L, Prvulovic D, Alves G, Kollmann B, et al. Cognitive and behavioural effects of physical exercise in psychiatric patients. Prog Neurobiol. 2012;96:46-68.

16. Read J, Gee A, Diggle J, Butler H. The interpersonal adverse effects reported by 1008 users of antidepressants; and the incremental impact of polypharmacy. Psychiatry Res. 2017;256:423-7.

17. Mota-Pereira J, Silverio J, Carvalho S, Ribeiro JC, Fonte D, Ramos J. Moderate exercise improves depression parameters in treatment-resistant patients with major depressive disorder. $\mathbf{J}$ Psychiatr Res. 2011;45:1005-11.

18. Abi-Dargham A. Schizophrenia: overview and dopamine dysfunction. J Clin Psychiatry. 2014;75:e31.

19. Goughari AS, Mazhari S, Pourrahimi AM, Sadeghi MM, Nakhaee N. Associations between components of metabolic syndrome and cognition in patients with schizophrenia. J Psychiatr Pract. 2015;21:190-7.

20. Klaus F, Kaiser S, Kirschner M. [Negative Symptoms in Schizophrenia - an Overview]. Ther Umsch. 2018;75:51-6.

21. Dauwan M, Begemann MJ, Heringa SM, Sommer IE. Exercise Improves Clinical Symptoms, Quality of Life, Global Functioning, and Depression in Schizophrenia: A Systematic Review and Meta-analysis. Schizophr Bull. 2016;42:588-99.

22. Focus on neurodegenerative disease. Nat Neurosci 2018; 21:1293.

23. Rubio-Perez JM, Morillas-Ruiz JM. A review: inflammatory process in Alzheimer's disease, role of cytokines. ScientificWorldJournal. 2012;2012:756357.

24. Law LL, Rol RN, Schultz SA, Dougherty RJ, Edwards DF, Koscik RL, et al. Moderate intensity physical activity associates with CSF biomarkers in a cohort at risk for Alzheimer's disease. Alzheimers Dement (Amst). 2018;10:188-95.
25. Prado Lima MG, Schimidt HL, Garcia A, Dare LR, Carpes FP, Izquierdo I, et al. Environmental enrichment and exercise are better than social enrichment to reduce memory deficits in amyloid beta neurotoxicity. Proc Natl Acad Sci USA. 2018;115: E2403-e9.

26. Belarbi K, Burnouf S, Fernandez-Gomez FJ, Laurent C, Lestavel $\mathrm{S}$, Figeac $\mathrm{M}$, et al. Beneficial effects of exercise in a transgenic mouse model of Alzheimer's disease-like Tau pathology. Neurobiol Dis. 2011;43:486-94.

27. Mudo G, Makela J, Di Liberto V, Tselykh TV, Olivieri M, Piepponen $\mathrm{P}$, et al. Transgenic expression and activation of PGC1alpha protect dopaminergic neurons in the MPTP mouse model of Parkinson's disease. Cell Mol Life Sci. 2012;69:1153-65.

28. Frazzitta G, Balbi P, Maestri R, Bertotti G, Boveri N, Pezzoli G. The beneficial role of intensive exercise on Parkinson disease progression. Am J Phys Med Rehabil. 2013;92:523-32.

29. Schenkman M, Moore CG, Kohrt WM, Hall DA, Delitto A, Comella CL, et al. Effect of high-intensity treadmill exercise on motor symptoms in patients with de novo Parkinson Disease: a phase 2 randomized clinical trial. JAMA Neurol. 2018;75:219-26.

30. Shin MS, Kim TW, Lee JM, Ji ES, Lim BV. Treadmill exercise alleviates nigrostriatal dopaminergic loss of neurons and fibers in rotenone-induced Parkinson rats. J Exerc Rehabil. 2017;13:30-5.

31. Al-Jarrah MD, Erekat NS. Parkinson disease-induced upregulation of apoptotic mediators could be attenuated in the skeletal muscle following chronic exercise training. NeuroRehabilitation. 2017;41:823-30.

32. Pearn ML, Niesman IR, Egawa J, Sawada A, Almenar-Queralt A, Shah SB, et al. Pathophysiology associated with traumatic brain injury: current treatments and potential novel therapeutics. Cell Mol Neurobiol. 2017;37:571-85.

33. Devine JM, Wong B, Gervino E, Pascual-Leone A, Alexander MP. Independent, community-based aerobic exercise training for people with moderate-to-severe traumatic brain injury. Arch Phys Med Rehabil. 2016;97:1392-7.

34. Esquenazi A, Lee S, Wikoff A, Packel A, Toczylowski T, Feeley J. A Comparison of Locomotor Therapy Interventions: Partial-Body Weight-Supported Treadmill, Lokomat, and G-EO Training in People With Traumatic Brain Injury. Pm R. 2017;9:839-46.

35. Seo TB, Kim BK, Ko IG, Kim DH, Shin MS, Kim CJ, et al. Effect of treadmill exercise on Purkinje cell loss and astrocytic reaction in the cerebellum after traumatic brain injury. Neurosci Lett. 2010;481:178-82.

36. Taylor JM, Montgomery MH, Gregory EJ, Berman NE. Exercise preconditioning improves traumatic brain injury outcomes. Brain Res. 2015;1622:414-29.

37. Ovbiagele B, Nguyen-Huynh MN. Stroke epidemiology: advancing our understanding of disease mechanism and therapy. Neurotherapeutics. 2011;8:319-29.

38. Juan J, Liu G, Willett WC, Hu FB, Rexrode KM, Sun Q. Whole grain consumption and risk of ischemic stroke: Results From 2 Prospective Cohort Studies. Stroke. 2017;48:3203-9.

39. Xing Y, Yang SD, Dong F, Wang MM, Feng YS, Zhang F. The beneficial role of early exercise training following stroke and possible mechanisms. Life Sci. 2018;198:32-7.

40. Reimers CD, Knapp G, Reimers AK. Exercise as stroke prophylaxis. Dtsch Arztebl Int. 2009;106:715-21.

41. Tiozzo E, Youbi M, Dave K, Perez-Pinzon M, Rundek T, Sacco $\mathrm{RL}$, et al. Aerobic, resistance, and cognitive exercise training poststroke. Stroke. 2015;46:2012-6.

42. Maass A, Duzel S, Brigadski T, Goerke M, Becke A, Sobieray U, et al. Relationships of peripheral IGF-1, VEGF and BDNF levels to exercise-related changes in memory, hippocampal perfusion and volumes in older adults. NeuroImage. 2016;131:142-54.

43. Taliaz D, Stall N, Dar DE, Zangen A. Knockdown of brainderived neurotrophic factor in specific brain sites precipitates 
behaviors associated with depression and reduces neurogenesis. Mol Psychiatry. 2009;15:80.

44. Voss MW, Vivar C, Kramer AF, van Praag H. Bridging animal and human models of exercise-induced brain plasticity. Trends Cogn Sci. 2013;17:525-44.

45. KhorshidAhmad T, Acosta C, Cortes C, Lakowski T, Gangadaran S, Namaka M. Transcriptional regulation of brain-derived neurotrophic factor (BDNF) by methyl $\mathrm{CpG}$ binding protein 2 (MeCP2): a novel mechanism for re-myelination and/or myelin repair involved in the treatment of multiple sclerosis (MS). Mol Neurobiol. 2016;53:1092-107.

46. Dinoff A, Herrmann N, Swardfager W, Gallagher D, Lanctôt $\mathrm{KL}$. The effect of exercise on resting concentrations of peripheral brain-derived neurotrophic factor (BDNF) in major depressive disorder: A meta-analysis. J Psychiatr Res. 2018;105:123-31.

47. Solvsten CAE, Daugaard TF, Luo Y, de Paoli F, Christensen JH, Nielsen AL. The effects of voluntary physical exercise-activated neurotrophic signaling in rat hippocampus on mRNA levels of downstream signaling molecules. J Mol Neurosci. 2017;62: $142-53$.

48. Rasmussen P, Brassard P, Adser H, Pedersen MV, Leick L, Hart E, et al. Evidence for a release of brain-derived neurotrophic factor from the brain during exercise. Exp Physiol. 2009;94:1062-9.

49. Wrann CD, White JP, Salogiannnis J, Laznik-Bogoslavski D, $\mathrm{Wu}$ J, Ma D, et al. Exercise induces hippocampal BDNF through a PGC-1alpha/FNDC5 pathway. Cell Metab. 2013;18:649-59.

50. Sleiman SF, Henry J, Al-Haddad R, El Hayek L, Abou Haidar E, Stringer $\mathrm{T}$, et al. Exercise promotes the expression of brain derived neurotrophic factor (BDNF) through the action of the ketone body beta-hydroxybutyrate. Elife 2016;5:e15092.

51. Ieraci A, Madaio AI, Mallei A, Lee FS, Popoli M. Brain-derived neurotrophic factor Val66Met human polymorphism impairs the beneficial exercise-induced neurobiological changes in mice. Neuropsychopharmacology. 2016;41:3070-9.

52. Gao Y, Zhao Y, Pan J, Yang L, Huang T, Feng X, et al. Treadmill exercise promotes angiogenesis in the ischemic penumbra of rat brains through caveolin-1/VEGF signaling pathways. Brain Res. 2014;1585:83-90.

53. Ding YH, Li J, Yao WX, Rafols JA, Clark JC, Ding Y. Exercise preconditioning upregulates cerebral integrins and enhances cerebrovascular integrity in ischemic rats. Acta Neuropathol. 2006;112:74-84.

54. Morland C, Andersson KA, Haugen OP, Hadzic A, Kleppa L, Gille A, et al. Exercise induces cerebral VEGF and angiogenesis via the lactate receptor HCAR1. Nat Commun. 2017;8:15557.

55. Rich B, Scadeng M, Yamaguchi M, Wagner PD, Breen EC. Skeletal myofiber vascular endothelial growth factor is required for the exercise training-induced increase in dentate gyrus neuronal precursor cells. J Physiol. 2017;595:5931-43.

56. Rubin LL, Staddon JM. The cell biology of the blood-brain barrier. Annu Rev Neurosci. 1999;22:11-28.

57. Cotman CW, Berchtold NC, Christie LA. Exercise builds brain health: key roles of growth factor cascades and inflammation. Trends Neurosci. 2007;30:464-72.

58. Fabel K, Fabel K, Tam B, Kaufer D, Baiker A, Simmons N, et al. VEGF is necessary for exercise-induced adult hippocampal neurogenesis. Eur J Neurosci. 2003;18:2803-12.

59. Carro E, Trejo JL, Nunez A, Torres-Aleman I. Brain repair and neuroprotection by serum insulin-like growth factor I. Mol Neurobiol. 2003;27:153-62.

60. Hadem IKH, Sharma R. Differential regulation of hippocampal IGF-1-associated signaling proteins by dietary restriction in aging mouse. Cell Mol Neurobiol. 2017;37:985-93.

61. Spielman LJ, Little JP, Klegeris A. Inflammation and insulin/ IGF-1 resistance as the possible link between obesity and neurodegeneration. J Neuroimmunol. 2014;273:8-21.
62. Tiwari AK, Souza RP, Muller DJ. Pharmacogenetics of anxiolytic drugs. J Neural Transm (Vienna). 2009;116:667-77.

63. Chennaoui M, Drogou C, Gomez-Merino D, Grimaldi B, Fillion G, Guezennec CY. Endurance training effects on 5-HT(1B) receptors mRNA expression in cerebellum, striatum, frontal cortex and hippocampus of rats. Neurosci Lett. 2001;307:33-6.

64. Kondo M, Nakamura Y, Ishida Y, Shimada S. The 5-HT3 receptor is essential for exercise-induced hippocampal neurogenesis and antidepressant effects. Mol Psychiatry. 2015;20: 1428-37.

65. Zimmer P, Stritt C, Bloch W, Schmidt FP, Hubner ST, Binnebossel S, et al. The effects of different aerobic exercise intensities on serum serotonin concentrations and their association with Stroop task performance: a randomized controlled trial. Eur J Appl Physiol. 2016;116:2025-34.

66. Young LW, Darios ES, Watts SW. An immunohistochemical analysis of SERT in the blood-brain barrier of the male rat brain. Histochem Cell Biol. 2015;144:321-9.

67. Audhya T, Adams JB, Johansen L. Correlation of serotonin levels in CSF, platelets, plasma, and urine. Biochim Biophys Acta. 2012;1820:1496-501.

68. Melancon MO, Lorrain D, Dionne IJ. Exercise increases tryptophan availability to the brain in older men age 57-70 years. Med Sci Sports Exerc. 2012;44:881-7.

69. Oxenkrug GF. Tryptophan kynurenine metabolism as a common mediator of genetic and environmental impacts in major depressive disorder: the serotonin hypothesis revisited 40 years later. Isr J Psychiatry Relat Sci. 2010;47:56-63.

70. Cervenka, I, Agudelo LZ, Ruas JL. Kynurenines: Tryptophan's metabolites in exercise, inflammation, and mental health. Science 2017;357:eaaf9794.

71. Agudelo LZ, Femenia T, Orhan F, Porsmyr-Palmertz M, Goiny M, Martinez-Redondo V, et al. Skeletal muscle PGC-1alpha1 modulates kynurenine metabolism and mediates resilience to stress-induced depression. Cell. 2014;159:33-45.

72. Johnstone RM, Adam M, Hammond JR, Orr L, Turbide C. Vesicle formation during reticulocyte maturation. Association of plasma membrane activities with released vesicles (exosomes). J Biol Chem. 1987;262:9412-20.

73. Pedersen L, Hojman P. Muscle-to-organ cross talk mediated by myokines. Adipocyte. 2012;1:164-7.

74. Delezie J, Handschin C. Endocrine crosstalk between skeletal muscle and the brain. Front Neurol. 2018;9:698.

75. Uldry M, Yang W, St-Pierre J, Lin J, Seale P, Spiegelman BM. Complementary action of the PGC-1 coactivators in mitochondrial biogenesis and brown fat differentiation. Cell Metab. 2006;3:333-41.

76. Andersson U, Scarpulla RC. Pgc-1-related coactivator, a novel, serum-inducible coactivator of nuclear respiratory factor 1dependent transcription in mammalian cells. Mol Cell Biol. 2001;21:3738-49.

77. Chen LW, Horng LY, Wu CL, Sung HC, Wu RT. Activating mitochondrial regulator PGC-1alpha expression by astrocytic NGF is a therapeutic strategy for Huntington's disease. Neuropharmacology. 2012;63:719-32.

78. Puddifoot C, Martel MA, Soriano FX, Camacho A, Vidal-Puig A, Wyllie DJ, et al. PGC-1alpha negatively regulates extrasynaptic NMDAR activity and excitotoxicity. J Neurosci. 2012;32:6995-7000.

79. Cheng A, Wan R, Yang JL, Kamimura N, Son TG, Ouyang X, et al. Involvement of PGC-1alpha in the formation and maintenance of neuronal dendritic spines. Nat Commun. 2012;3:1250.

80. Bostrom P, Wu J, Jedrychowski MP, Korde A, Ye L, Lo JC, et al. A PGC1-alpha-dependent myokine that drives brown-fatlike development of white fat and thermogenesis. Nature. 2012;481:463-8. 
81. Finck BN, Kelly DP. PGC-1 coactivators: inducible regulators of energy metabolism in health and disease. $\mathbf{J}$ Clin Invest. 2006;116:615-22.

82. Teufel A, Malik N, Mukhopadhyay M, Westphal H. Frcp1 and Frcp2, two novel fibronectin type III repeat containing genes. Gene. 2002;297:79-83.

83. Asadi Y, Gorjipour F, Behrouzifar S, Vakili A. Irisin peptide protects brain against ischemic injury through reducing apoptosis and enhancing BDNF in a rodent model of stroke. Neurochem Res. 2018. https://doi.org/10.1007/s11064-018-2569-9. [Epub ahead of print]

84. Siteneski A, Cunha MP, Lieberknecht V, Pazini FL, Gruhn K, Brocardo PS, et al. Central irisin administration affords antidepressant-like effect and modulates neuroplasticity-related genes in the hippocampus and prefrontal cortex of mice. Prog Neuropsychopharmacol Biol Psychiatry. 2018;84:294-303.

85. Sloane BF. Cathepsin B and cystatins: evidence for a role in cancer progression. Semin Cancer Biol. 1990;1:137-52.

86. Yang WE, Ho CC, Yang SF, Lin SH, Yeh KT, Lin CW, et al. Cathepsin B expression and the correlation with clinical aspects of oral squamous cell carcinoma. PLoS ONE. 2016;11:e0152165.

87. Moon HY, Becke A, Berron D, Becker B, Sah N, Benoni G, et al. Running-induced systemic cathepsin B secretion is associated with memory function. Cell Metab. 2016;24:332-40.

88. Kawauchi T. Cellullar insights into cerebral cortical development: focusing on the locomotion mode of neuronal migration. Front Cell Neurosci. 2015;9:394.

89. Suzuki WA. How Body Affects Brain. Cell Metab. 2016;24: 192-3.

90. Fisher FM, Maratos-Flier E. Understanding the Physiology of FGF21. Annu Rev Physiol. 2016;78:223-41.

91. Tanimura Y, Aoi W, Takanami Y, Kawai Y, Mizushima K, Naito $\mathrm{Y}$, et al. Acute exercise increases fibroblast growth factor 21 in metabolic organs and circulation. Physiol Rep 2016;4:e12828.

92. Hsuchou H, Pan W, Kastin AJ. The fasting polypeptide FGF21 can enter brain from blood. Peptides. 2007;28:2382-6.

93. Tan BK, Hallschmid M, Adya R, Kern W, Lehnert H, Randeva HS. Fibroblast growth factor 21 (FGF21) in human cerebrospinal fluid: relationship with plasma FGF21 and body adiposity. Diabetes. 2011;60:2758-62.

94. Bookout AL, de Groot MH, Owen BM, Lee S, Gautron L, Lawrence HL, et al. FGF21 regulates metabolism and circadian behavior by acting on the nervous system. Nat Med. 2013;19:1147-52.

95. Kuroda M, Muramatsu R, Maedera N, Koyama Y, Hamaguchi M, Fujimura H, et al. Peripherally derived FGF21 promotes remyelination in the central nervous system. J Clin Invest. 2017;127:3496-509.

96. Aoi W, Naito Y, Takagi T, Tanimura Y, Takanami Y, Kawai Y, et al. A novel myokine, secreted protein acidic and rich in cysteine (SPARC), suppresses colon tumorigenesis via regular exercise. Gut. 2013;62:882-9.

97. Campolongo M, Benedetti L, Podhajcer OL, Pitossi F, Depino AM. Hippocampal SPARC regulates depression-related behavior. Genes Brain Behav. 2012;11:966-76.

98. Ma CH, Bampton ET, Evans MJ, Taylor JS. Synergistic effects of osteonectin and brain-derived neurotrophic factor on axotomized retinal ganglion cells neurite outgrowth via the mitogenactivated protein kinase-extracellular signal-regulated kinase 1/2 pathways. Neuroscience. 2010;165:463-74.

99. Lloyd-Burton SM, York EM, Anwar MA, Vincent AJ, Roskams AJ. SPARC regulates microgliosis and functional recovery following cortical ischemia. J Neurosci. 2013;33:4468-81.

100. Liang Z, Zhao Y, Ruan L, Zhu L, Jin K, Zhuge Q, et al. Impact of aging immune system on neurodegeneration and potential immunotherapies. Prog Neurobiol. 2017;157:2-28.
101. Perry VH. Contribution of systemic inflammation to chronic neurodegeneration. Acta Neuropathol. 2010;120:277-86.

102. Rethorst CD, Toups MS, Greer TL, Nakonezny PA, Carmody TJ, Grannemann BD, et al. Pro-inflammatory cytokines as predictors of antidepressant effects of exercise in major depressive disorder. Mol Psychiatry. 2013;18:1119-24.

103. Mazur-Bialy AI, Bilski J, Pochec E, Brzozowski T. New insight into the direct anti-inflammatory activity of a myokine irisin against proinflammatory activation of adipocytes. Implication for exercise in obesity. J Physiol Pharmacol. 2017;68:243-51.

104. Ortega E. The "bioregulatory effect of exercise" on the innate/ inflammatory responses. J Physiol Biochem. 2016;72:361-9.

105. Li F, Pendy JT, Jr., Ding JN, Peng C, Li X, Shen J, et al. Exercise rehabilitation immediately following ischemic stroke exacerbates inflammatory injury. Neurol Res. 2017;39:530-7.

106. Gomes da Silva S, Simoes PS, Mortara RA, Scorza FA, Cavalheiro EA, da Graca Naffah-Mazzacoratti M, et al. Exerciseinduced hippocampal anti-inflammatory response in aged rats. $\mathrm{J}$ Neuroinflamm. 2013;10:61.

107. Souza LC, Filho CB, Goes AT, Fabbro LD, de Gomes MG, Savegnago L, et al. Neuroprotective effect of physical exercise in a mouse model of Alzheimer's disease induced by beta-amyloid(1)(-)(4)(0) peptide. Neurotox Res. 2013;24:148-63.

108. Curry A, Guo M, Patel R, Liebelt B, Sprague S, Lai Q, et al. Exercise pre-conditioning reduces brain inflammation in stroke via tumor necrosis factor-alpha, extracellular signal-regulated kinase 1/2 and matrix metalloproteinase-9 activity. Neurol Res. 2010;32:756-62.

109. Chio CC, Lin HJ, Tian YF, Chen YC, Lin MT, Lin CH, et al. Exercise attenuates neurological deficits by stimulating a critical HSP70/NF-kappaB/IL-6/synapsin I axis in traumatic brain injury rats. J Neuroinflamm. 2017;14:90.

110. Sertie RA, Andreotti S, Proenca AR, Campana AB, Lima-Salgado TM, Batista ML, Jr., et al. Cessation of physical exercise changes metabolism and modifies the adipocyte cellularity of the periepididymal white adipose tissue in rats. J Appl Physiol (1985). 2013;115:394-402.

111. Yau SY, Li A, Hoo RL, Ching YP, Christie BR, Lee TM, et al. Physical exercise-induced hippocampal neurogenesis and antidepressant effects are mediated by the adipocyte hormone adiponectin. Proc Natl Acad Sci USA. 2014;111:15810-5.

112. Henze K, Martin W. Evolutionary biology: essence of mitochondria. Nature. 2003;426:127-8.

113. Twig G, Shirihai OS. The interplay between mitochondrial dynamics and mitophagy. Antioxid Redox Signal. 2011;14: 1939-51.

114. Laker RC, Drake JC, Wilson RJ, Lira VA, Lewellen BM, Ryall $\mathrm{KA}$, et al. Ampk phosphorylation of Ulk1 is required for targeting of mitochondria to lysosomes in exercise-induced mitophagy. Nat Commun. 2017;8:548.

115. Marques-Aleixo I, Oliveira PJ, Moreira PI, Magalhaes J, Ascensao A. Physical exercise as a possible strategy for brain protection: evidence from mitochondrial-mediated mechanisms. Prog Neurobiol. 2012;99:149-62.

116. Bayod S, Del Valle J, Canudas AM, Lalanza JF, Sanchez-Roige $\mathrm{S}$, Camins A, et al. Long-term treadmill exercise induces neuroprotective molecular changes in rat brain. J Appl Physiol (1985). 2011;111:1380-90.

117. Steiner JL, Murphy EA, McClellan JL, Carmichael MD, Davis JM. Exercise training increases mitochondrial biogenesis in the brain. J Appl Physiol (1985). 2011;111:1066-71.

118. Vainshtein A, Tryon LD, Pauly M, Hood DA. Role of PGC-1alpha during acute exercise-induced autophagy and mitophagy in skeletal muscle. Am J Physiol Cell Physiol. 2015;308:C710-9. 
119. Zhang C, Ji Q, Yang Y, Li Q, Wang Z. Exosome: Function and Role in Cancer Metastasis and Drug Resistance. Technol Cancer Res Treat. 2018;17:1533033818763450.

120. Safdar, A, MA Tarnopolsky. Exosomes as mediators of the systemic adaptations to endurance exercise. Cold Spring Harb Perspect Med. 2018;8:a029827.

121. Whitham M, Parker BL, Friedrichsen M, Hingst JR, Hjorth M, Hughes WE, et al. Extracellular vesicles provide a means for tissue crosstalk during exercise. Cell Metab. 2018;27:237-51.e4.

122. Aswad H, Forterre A, Wiklander OP, Vial G, Danty-Berger E, Jalabert A, et al. Exosomes participate in the alteration of muscle homeostasis during lipid-induced insulin resistance in mice. Diabetologia. 2014;57:2155-64.

123. Safdar A, Saleem A, Tarnopolsky MA. The potential of endurance exercise-derived exosomes to treat metabolic diseases. Nat Rev Endocrinol. 2016;12:504-17.

124. Chen CC, Liu L, Ma F, Wong CW, Guo XE, Chacko JV, et al. Elucidation of exosome migration across the blood-brain barrier model in vitro. Cell Mol Bioeng. 2016;9:509-29.

125. Yang T, Martin P, Fogarty B, Brown A, Schurman K, Phipps R, et al. Exosome delivered anticancer drugs across the blood-brain barrier for brain cancer therapy in Danio rerio. Pharm Res. 2015;32:2003-14.

126. Haney MJ, Klyachko NL, Zhao Y, Gupta R, Plotnikova EG, He $\mathrm{Z}$, et al. Exosomes as drug delivery vehicles for Parkinson's disease therapy. J Control Release. 2015;207:18-30.

127. Alvarez-Erviti L, Seow Y, Yin H, Betts C, Lakhal S, Wood MJ. Delivery of siRNA to the mouse brain by systemic injection of targeted exosomes. Nat Biotechnol. 2011;29:341-5.

128. Rendeiro C, Rhodes JS. A new perspective of the hippocampus in the origin of exercise-brain interactions. Brain Struct Funct. 2018;223:2527-45.

129. Ganguly K, Poo MM. Activity-dependent neural plasticity from bench to bedside. Neuron. 2013;80:729-41.

130. Cameron HA, McEwen BS, Gould E. Regulation of adult neurogenesis by excitatory input and NMDA receptor activation in the dentate gyrus. J Neurosci. 1995;15:4687-92.

131. Atwood CS, Bowen RL. The endocrine dyscrasia that accompanies menopause and andropause induces aberrant cell cycle signaling that triggers re-entry of post-mitotic neurons into the cell cycle, neurodysfunction, neurodegeneration and cognitive disease. Horm Behav. 2015;76:63-80.

132. Lee TH, Jang MH, Shin MC, Lim BV, Kim YP, Kim H, et al. Dependence of rat hippocampal c-Fos expression on intensity and duration of exercise. Life Sci. 2003;72:1421-36.

133. Chen Z, Resnik E, McFarland JM, Sakmann B, Mehta MR. Speed controls the amplitude and timing of the hippocampal gamma rhythm. PLoS ONE. 2011;6:e21408.

134. Vanderwolf $\mathrm{CH}$. Hippocampal electrical activity and voluntary movement in the rat. Electroencephalogr Clin Neurophysiol. 1969;26:407-18.

135. Clark PJ, Bhattacharya TK, Miller DS, Rhodes JS. Induction of c-Fos, Zif268, and Arc from acute bouts of voluntary wheel running in new and pre-existing adult mouse hippocampal granule neurons. Neuroscience. 2011;184:16-27.

136. Handa RJ, Nunley KM, Bollnow MR. Induction of c-fos mRNA in the brain and anterior pituitary gland by a novel environment. Neuroreport. 1993;4:1079-82.

137. Oladehin A, Waters RS. Location and distribution of Fos protein expression in rat hippocampus following acute moderate aerobic exercise. Exp Brain Res. 2001;137:26-35.

138. Hirase H, Czurko A, Csicsvari J, Buzsaki G. Firing rate and theta-phase coding by hippocampal pyramidal neurons during 'space clamping'. Eur J Neurosci. 1999;11:4373-80.

139. Fuhrmann F, Justus D, Sosulina L, Kaneko H, Beutel T, Friedrichs $\mathrm{D}$, et al. Locomotion, theta oscillations, and the speed-correlated firing of hippocampal neurons are controlled by a medial septal glutamatergic circuit. Neuron. 2015;86:1253-64.

140. Geisler C, Robbe D, Zugaro M, Sirota A, Buzsaki G. Hippocampal place cell assemblies are speed-controlled oscillators. Proc Natl Acad Sci USA. 2007;104:8149-54.

141. Song EY, Kim YB, Kim YH, Jung MW. Role of active movement in place-specific firing of hippocampal neurons. Hippocampus. 2005;15:8-17.

142. Misgeld U, Frotscher M. Postsynaptic-GABAergic inhibition of non-pyramidal neurons in the guinea-pig hippocampus. Neuroscience. 1986;19:193-206.

143. Oddie SD, Stefanek W, Kirk IJ, Bland BH. Intraseptal procaine abolishes hypothalamic stimulation-induced wheel-running and hippocampal theta field activity in rats. J Neurosci. 1996; 16:1948-56.

144. Morris T, Gomes Osman J, Tormos Munoz JM, Costa Miserachs D, Pascual Leone A. The role of physical exercise in cognitive recovery after traumatic brain injury: A systematic review. Restor Neurol Neurosci. 2016;34:977-88.

145. Shulman LM, Katzel LI, Ivey FM, Sorkin JD, Favors K, Anderson KE, et al. Randomized clinical trial of 3 types of physical exercise for patients with Parkinson disease. JAMA Neurol. 2013;70:183-90.

146. Barha CK, Davis JC, Falck RS, Nagamatsu LS, Liu-Ambrose T. Sex differences in exercise efficacy to improve cognition: A systematic review and meta-analysis of randomized controlled trials in older humans. Front Neuroendocrinol. 2017; 46:71-85.

147. Cahn BR, Goodman MS, Peterson CT, Maturi R, Mills PJ. Yoga, meditation and mind-body health: increased BDNF, cortisol awakening response, and altered inflammatory marker expression after a 3-month yoga and meditation retreat. Front Hum Neurosci. 2017;11:315.

148. Sungkarat S, Boripuntakul S, Kumfu S, Lord SR, Chattipakorn N. Tai Chi Improves Cognition and Plasma BDNF in Older Adults With Mild Cognitive Impairment: A Randomized Controlled Trial. Neurorehabil Neural Repair. 2018;32:142-9.

149. Oh CU, Kim NC. Effects of T'ai Chi on Serotonin, Nicotine Dependency, Depression, and Anger in Hospitalized Alcohol-Dependent Patients. J Altern Complement Med. 2016; 22:957-63.

150. Lim SA, Cheong KJ. Regular yoga practice improves antioxidant status, immune function, and stress hormone releases in young healthy people: a randomized, double-blind, controlled pilot study. J Altern Complement Med. 2015;21:530-8.

151. Irwin MR, Olmstead R, Breen EC, Witarama T, Carrillo C, Sadeghi N, et al. Cognitive behavioral therapy and tai chi reverse cellular and genomic markers of inflammation in late-life insomnia: a randomized controlled trial. Biol Psychiatry. 2015;78:721-9.

152. King DE, Carek P, Mainous AG, 3rd, Pearson WS. Inflammatory markers and exercise: differences related to exercise type. Med Sci Sports Exerc. 2003;35:575-81.

153. Li MY, Huang MM, Li SZ, Tao J, Zheng GH, Chen LD. The effects of aerobic exercise on the structure and function of DMNrelated brain regions: a systematic review. Int $\mathrm{J}$ Neurosci. 2017;127:634-49.

154. Kim YS, Shin SK, Hong SB, Kim HJ. The effects of strength exercise on hippocampus volume and functional fitness of older women. Exp Gerontol. 2017;97:22-8.

155. Tao J, Liu J, Liu W, Huang J, Xue X, Chen X, et al. Tai Chi Chuan and Baduanjin Increase Grey Matter Volume in Older Adults: A Brain Imaging Study. J Alzheimers Dis. 2017;60:389-400.

156. Gotink RA, Vernooij MW, Ikram MA, Niessen WJ, Krestin GP, Hofman A, et al. Meditation and yoga practice are associated 
with smaller right amygdala volume: the Rotterdam study. Brain Imaging Behav 2018;12:1631-9.

157. Cassilhas RC, Lee KS, Fernandes J, Oliveira MG, Tufik S, Meeusen R, et al. Spatial memory is improved by aerobic and resistance exercise through divergent molecular mechanisms. Neuroscience. 2012;202:309-17.

158. Nokia MS, Lensu S, Ahtiainen JP, Johansson PP, Koch LG, Britton SL, et al. Physical exercise increases adult hippocampal neurogenesis in male rats provided it is aerobic and sustained. $\mathrm{J}$ Physiol. 2016;594:1855-73.
159. Millay DP, Olson EN. Making muscle or mitochondria by selective splicing of PGC-1alpha. Cell Metab. 2013;17:3-4.

160. Ruas JL, White JP, Rao RR, Kleiner S, Brannan KT, Harrison $\mathrm{BC}$, et al. A PGC-1alpha isoform induced by resistance training regulates skeletal muscle hypertrophy. Cell. 2012;151: 1319-31.

161. Vargas-Ortiz K, Perez-Vazquez V, Figueroa A, Diaz FJ. Aerobic training but no resistance training increases SIRT3 in skeletal muscle of sedentary obese male adolescents. Eur J Sport Sci. 2018;18:226-34. 